\title{
ANÁLISE DO PERFIL DOS INCÊNDIOS FLORESTAIS NO PARQUE ESTADUAL DA SERRA DO BRIGADEIRO E ENTORNO (MG)
}

\section{PROFILE ANALYSIS OF FOREST FIRES IN THE SERRA DO BRIGADEIRO STATE PARK AND SURROUNDINGS AREA (MG)}

Fillipe Tamiozzo Pereira Torres ${ }^{1}$ Carlos Moreira Miquelino Eleto Torres ${ }^{2}$ Gumercindo Souza Lima ${ }^{2}$ Sebastião Venâncio Martins ${ }^{2}$ Ana Eurica de Oliveira Mendes ${ }^{3}$ Michele Tidisco Padovani ${ }^{4}$ Rafael Gomes Siqueira ${ }^{5}$ Gilberto Fialho Moreira ${ }^{6}$ Sebastião Renato Valverde ${ }^{2}$

\section{RESUMO}

O fogo é um dos principais problemas do bioma Mata Atlântica, mesmo em áreas protegidas, como as Unidades de Conservação (UCs). Sendo assim, o objetivo deste estudo foi conhecer o perfil dos incêndios florestais no Parque Estadual da Serra do Brigadeiro (PESB) e entorno, bem como suas respostas frente às variações ambientais. Para isto, foram analisadas as informações dos Registros de Ocorrências de Incêndios (ROIs) e suas inter-relações com os sistemas ambientais do PESB, por meio das análises dos planos espaciais (uso e cobertura do solo e relevo) e temporais (elementos climatológicos). De acordo com os resultados, $38 \%$ dos registros apresentaram as causas dos incêndios, destas, $77 \%$ foram identificadas como antrópicas. Analisando-se a área queimada, observou-se o maior número de ocorrências dentro da classe III (4,1 - 40,0 ha). A vegetação herbácea, por conta de suas características favoráveis, foi a mais atingida. O relevo também influenciou as ocorrências, a declividade, exposição das vertentes e altitude participaram significativamente do regime de incêndios no parque. A atividade antrópica mostrou sua influência com o aumento do tamanho da área queimada nas proximidades de vias de acesso (trilhas e estradas). Já o clima controlou a disposição temporal das ocorrências, no qual períodos de menor umidade relativa do ar tornaram os meses de agosto e setembro como os pertencentes à estação normal de perigo de incêndios e a precipitação acumulada determinou os anos mais problemáticos. Os resultados aqui apresentados fornecerão informações para subsidiar a tomada de decisões de forma mais segura e confiável na prevenção das ocorrências de incêndios florestais no PESB e entorno, visto que contribuem com um melhor entendimento dos fatores que controlam as ocorrências de incêndios na região.

Palavras-chave: fogo; PESB; prevenção de incêndios; causas.

1 Geógrafo, Dr., Professor do Departamento de Engenharia Florestal, Universidade Federal de Viçosa, Av. Purdue, s/n, CEP 36570-900, Viçosa (MG), Brasil. tamiozzo@ufv.br

2 Engenheiro Florestal, Dr., Professor do Departamento de Engenharia Florestal, Universidade Federal de Viçosa, Av. Purdue, s/n, CEP 36570-900, Viçosa (MG), Brasil. carlos.eleto@ufv.br / gslima@ufv.br / venancio@ufv.br / valverde@ufv.br

3 Agroecóloga, MSc., Administrativo do Parque Estadual da Serra do Brigadeiro, Vila Giannett, casa 51, CEP 36570-000, Viçosa (MG), Brasil. anamendes33@yahoo.com.br

4 Geógrafa, MSc., Administrativo do Parque Estadual da Serra do Brigadeiro, Vila Giannett, casa 51, CEP 36570000, Viçosa (MG), Brasil. mipadovani18@gmail.com

5 Geógrafo, Estagiário do Centro de Estudos e Desenvolvimento Florestal CEDEF/IEF, Vila Giannett, casa 51, CEP 36570-000, Viçosa (MG), Brasil. rafael.geo.siqueira@gmail.com

6 Geógrafo, Doutorando, Coordenador do Centro de Estudos e Desenvolvimento Florestal CEDEF/IEF, Vila Giannett, casa 51, CEP 36570-000, Viçosa (MG), Brasil. cedef.ief@gmail.com

Recebido para publicação em 20/07/2016 e aceito em 6/07/2017

Ci. Fl., v. 28, n. 3, jul. - set., 2018 


\section{ABSTRACT}

Fire is one of the main problems of the Atlantic Rainforest biome, even in protected areas such as Protected Areas (PAs or UC, in Portuguese). Thus, the aim of this study was to know the profile of forest fires in the Serra do Brigadeiro State Park (PESB-MG) and surroundings, as well as their responses in environmental variations. For this, we analyzed the information of Fire Incident Report (FIR or ROI, in Portuguese) and their interrelations with the environmental PESB systems through the analysis of spatial plans (land use and land cover and topography) and temporal (climatological elements). According to the results, only $38 \%$ of the records showed the causes of fires, of these, $77 \%$ were identified as anthropic. Analyzing the burned area, there was the highest number of occurrences within the class III ( $4.1-40.0$ ha). The herbaceous vegetation, because of their favorable characteristics, was hardest hit. The relief also influenced the events, slope, aspect and height participated significantly in the fire regime in the Park. The anthropic activity showed its influence to increase the size of the area burned in the vicinity of access routes. The climate controlled the temporal arrangement of events, where periods of lower Relative humidity of air, made the months of August and September as belonging to the normal fire season and accumulated rainfall determined the most problematic years. The results presented here provide information to support the making of more safe and reliable decisions in the prevention of forest fire occurrences in PESB and surroundings, as they contribute to a better understanding of the factors that control the fire occurrences in the region.

Keywords: fire; PESB; fire prevention; causes.

\section{INTRODUÇÃO}

O fogo progressivamente vem modelando a paisagem, modificando a estrutura, a composição, o poder de regeneração de comunidades vegetais e reduzindo drasticamente as florestas e outros ambientes naturais, sobretudo no Bioma Mata Atlântica (AXIMOFF; RODRIGUES, 2011). Ainda para os autores, este bioma se encontra reduzido a cerca de $16 \%$ de sua cobertura florestal original e a maior parte dos remanescentes florestais está em áreas protegidas, embora continuem a sofrer constante pressão antrópica.

Apesar de protegidas por lei, a ocorrência de incêndios florestais é uma das ameaças contínuas aos objetivos das Unidades de Conservação (UCs) (FIEDLER; MERLO; MEDEIROS, 2006). Para Aximoff e Rodrigues (2011), as UCs sofrem anualmente com incêndios principalmente em consequência de atividades antrópicas, causando danos a vários componentes do ambiente, que geram prejuízos do ponto de vista científico, ambiental, social e econômico.

Mesmo na Europa, as áreas protegidas também sofrem com os incêndios, geralmente provocados por conflitos com a população local. As razões têm sido a falta de compreensão e falta de benefícios percebidos nos planos de gestão destas áreas (FUENTES-SANTOS; MAREY-PÉREZ; GONZÁLEZ-MANTEIGA, 2013).

Além dos conflitos, no Brasil, as causas de incêndios em UCs têm sido principalmente devido ao uso incorreto do fogo para renovação de pastagens e limpeza de restos de cultura nas propriedades vizinhas (PEREIRA; FIEDLER; MEDEIROS, 2004).

Com uma quantidade limitada de equipamentos e recursos financeiros e humanos, os gestores das UCs devem decidir a aplicação mais eficiente de subsídios em ações como a prevenção (campanhas de educação ambiental), gestão de combustível (queima prescrita e tratamentos mecânicos), pré-supressão (planejamento e preparação, recrutamento e treinamento de bombeiros, manutenção de aceiros e pontos de água), supressão e medidas de restauração (MAVSAR; CABÁN; FARRERAS, 2010).

De acordo com Collins et al. (2013), políticas com foco na supressão dos incêndios proporcionam benefícios imediatos, mas podem ter eficiência inferior ao longo do tempo quando comparadas com investimentos em prevenção. Neste contexto, para estabelecer políticas de controle e prevenção, faz-se necessário conhecer quando e porque ocorrem, ou seja, o perfil dos incêndios florestais. As estatísticas são as principais ferramentas para se traçar seu perfil. Com esses dados, planeja-se o controle de modo mais eficiente; sem eles, subestimam-se ou superestimam-se os gastos relacionados à proteção do ambiente, colocando em risco a sobrevivência das florestas (SANTOS; SOARES; BATISTA, 2006).

Segundo Irland (2013), levantar o histórico do fogo e compreender o caráter estatístico do tamanho 
e da área de ocorrência dos incêndios florestais é importante para os programas de proteção florestal. É amplamente reconhecido que quanto mais se entender sobre o comportamento do fogo e sua resposta às condições ambientais, mais se poderá antecipar situações perigosas, ou impactos de grande magnitude, e mais acertadas serão as decisões sobre a gestão de combustíveis e dos incêndios (LINN et al., 2012).

Contudo, para Pezzatti et al. (2013), todas as regiões, mesmo as mais próximas, têm o seu próprio contexto específico de comportamento do fogo e, portanto, enfatizam a necessidade de estudos das estatísticas de incêndios locais, a fim de compreender melhor as ocorrências, o que leva a medidas mais eficientes na diminuição dos danos causados. Corroborando, para Aximoff e Rodrigues (2011), estudos que identifiquem, por exemplo, o regime de fogo, conceituado como o padrão de intensidade, frequência e sazonalidade, as causas, os agentes causadores, os locais de ocorrência e a extensão das áreas queimadas são de extrema importância para contribuir no desenvolvimento de ações de prevenção e combate aos incêndios nas UCs.

Diante do exposto, o objetivo deste estudo foi conhecer o perfil dos incêndios florestais no Parque Estadual da Serra do Brigadeiro, bem como suas respostas frente às variações ambientais, fornecendo informações para subsidiar a tomada de decisões de forma mais segura e confiável.

\section{MATERIAL E MÉTODO}

O Parque Estadual da Serra do Brigadeiro (PESB) está localizado na Zona da Mata (Minas Gerais, Brasil), inserido nos municípios de Araponga, Fervedouro, Miradouro, Ervália, Sericita, Pedra Bonita, Muriaé e Divino. Possui uma área de 14.984 hectares, entre os meridianos $42^{\circ} 20^{\prime}$ e $42^{\circ} 40^{\prime} \mathrm{W}$, e os paralelos $20^{\circ} 20^{\prime}$ e $21^{\circ} 00^{\prime}$ S. Localiza-se em uma elevação no extremo norte da Serra da Mantiqueira, com altitude variando entre 1.000 e 2.000 metros, com vales profundos e pequenos planaltos que exercem influência nas características microclimáticas do parque. O período chuvoso ocorre durante os meses de novembro a março, que também é o mais quente, e o período mais seco de abril a setembro, sendo o trimestre entre junho e agosto o mais frio (PAULA et al., 2015). Para este estudo, além da área do parque, foi analisado também um buffer que se estende a um quilômetro (15.134 hectares) a partir dos limites da UC, totalizando 30.118 hectares de análise.

Para a obtenção das informações sobre a declividade e exposição das vertentes, foi gerado no software ArcGIS 10.1, um Modelo Digital de Elevação (MDE) por meio da interpolação das curvas de nível, com equidistância de 20 metros, e dos pontos cotados extraídos das quatro cartas planialtimétricas produzidas pelo Instituto Brasileiro de Geografia e Estatística (IBGE) na escala de 1:50.000 (SF-23-XB-V-2; SF-23-X-B-V-4; SF-23-X-B-VI-1; SF-23-X-B-VI-3), que abrangem a área de estudo. Antes da geração do modelo numérico, foi necessária a realização de uma correção topológica semiautomática dos arquivos digitais das curvas de nível, visando à conexão dos vetores nas adjacências das cartas e o ajuste das linhas nos locais em que foram encontradas sobreposições das curvas. Já as informações sobre o uso e cobertura do solo, foram obtidas por meio da fotointerpretação de imagens orbitais do ano de 2011 da constelação RapidEye, de cinco metros de resolução, cujos códigos são 2329425, 2329525, 2329526 e 2329626, e adquiridas junto à Secretaria de Estado de Meio Ambiental e Desenvolvimento Sustentável de Minas Gerais (SEMAD-MG).

A partir destas imagens foram identificadas as seguintes classes: agricultura (culturas agrícolas), Campo de Altitude sobre afloramento rochoso (campo sobre rocha), Campo de Altitude sobre solo (campo sobre solo), floresta de produção (eucalipto), Floresta Estacional Semidecidual (mata nativa) e pastagem de gramíneas exóticas (pastagem). As 34 ocorrências de incêndios registradas de 2007 a 2015, em formato polígono, foram adquiridos na base de dados do Centro de Estudos e Desenvolvimento Florestal do Instituto Estadual de Florestas (CEDEF/IEF - MG), tendo como fonte os levantamentos de campo para os Registros de Ocorrências de Incêndios (ROIs) do PESB.

A ordenação por tamanho de área queimada foi feita em cinco classes, segundo a classificação adotada pelo Canadian Forest Service (RAMSEY; HIGGINS, 1981): classe I, $<0,1$ ha; classe II, 0,1 a 4,0 ha; classe III, 4,1 a 40,0 ha; classe IV, 40,1 a 200,0 ha; e classe V, >200,0 ha.

Parte dos resultados foram obtidos por meio dos valores encontrados pelo ArcGIS pela interposição dos polígonos das áreas queimadas, com os planos de informação do uso e cobertura do solo, exposição 
das vertentes ao sol, declividade e proximidade de trilhas e estradas. Com relação à comparação das médias mensais de ocorrências de incêndios, para determinar os meses que compõem a estação normal de perigo de incêndios, foi utilizado o teste Scott Knott a 5\% de probabilidade.

Para a análise da influência climática sobre os incêndios na região, os dados meteorológicos foram obtidos da estação meteorológica localizada no campus da Universidade Federal de Viçosa $(38 \mathrm{~km}$ do PESB) e os valores mensais foram correlacionados com o número de ocorrências mensais, determinando aqueles que mais influenciam as ocorrências.

\section{RESULTADOS E DISCUSSÃO}

Com relação às causas, das 34 ocorrências registradas, 13 tiveram identificação, destas, quatro foram identificadas como incendiários, quatro como queima para limpeza, três como raios e duas como diversos. No Bohemian Switzerland National Park (BSNP), noroeste da República Tcheca, Adámek et al. (2015) observaram que as causas da maioria dos incêndios foram desconhecidas ou não declaradas (83\%), $10 \%$ causadas por turistas, $4 \%$ por cigarros e $3 \%$ por raios. Também no Parque Nacional do Itatiaia, a maior parte dos incêndios teve causa e agentes desconhecidos $(88,2 \%)$, sendo que do restante das ocorrências, $82,6 \%$ foram provocadas por humanos, a maior parte destas, para limpeza e renovação da pastagem $(42,8 \%)$ (AXIMOFF; RODRIGUES, 2011). Para os autores, a falta de informações sobre a causa e o agente causador é consequência da precariedade do sistema de perícias. As perícias são importantes, pois possibilitam a identificação da origem e das causas dos incêndios, permitindo a realização de um diagnóstico para a remediação do problema. Quanto às causas dos grandes incêndios no sul da França, a proporção de causas desconhecidas foi elevada até 2003, diminuindo consideravelmente desde então, graças às investigações mais eficientes (GANTEAUME; JAPPIOT, 2013).

Dentre as causas identificadas, observa-se a grande influência antrópica, fato recorrente em outras partes do mundo. As principais causas de incêndios florestais no Japão estão relacionadas às atividades humanas, como a queima de lixo, queimadas agrícolas, incendiários, fumantes, e fogos de recreação (OKANO; YAMANO, 2015). Mais de 95\% dos incêndios na Europa têm origem antrópica. Uma análise das principais causas mostram que as mais comuns são práticas agrícolas, seguidas por negligência e incendiários (SAN-MIGUEL-AYANZ; MORENO; CAMIA, 2013). Na Tailândia, existe a estimativa de que as atividades antrópicas são responsáveis por mais de 99\% dos incêndios florestais (HOARE, 2004).

Segundo Medeiros e Fiedler (2004), a situação fundiária não regularizada dentro das UCs aumenta a pressão sobre a conservação dos seus recursos naturais. Assim, Aximoff e Rodrigues (2011) identificam que a regularização fundiária interna e do entorno é ação fundamental para a prevenção dos incêndios em Unidades de Conservação. Os autores afirmam ainda que se deve realizar o zoneamento das regiões mais críticas aos incêndios em vegetação nas UCs, identificando as áreas que deveriam receber prioridade nas ações de prevenção, fiscalização e controle.

De acordo com Mendes (2014), a maioria das ocorrências de incêndios no entorno e na área do PESB ocorre na região norte (municípios de Sericita, Pedra Bonita e Divino). Para a autora, isto se deve à expansão agrícola na região, a cultura e práticas de manejo das terras pelas famílias agricultoras e ao baixo custo deste manejo.

Analisando-se a Tabela 1, observa-se que o maior número de ocorrências no PESB e entorno foram observados na classe III $(4,1-40,0$ ha), sendo a maior área queimada dentro da classe IV $(40,1-200,0$ ha). No norte de Minas Gerais, Pereira et al. (2013) observaram uma maior concentração de ocorrências de incêndios nas classes de menor tamanho, fato este que pode indicar a eficiência do controle das áreas atingidas pelo fogo, por outro lado, as áreas queimadas com grandes dimensões, apesar da baixa frequência, corresponderam a $26,30 \%$ do total de área afetada pelo fogo, e a soma de todas as áreas queimadas na classe de tamanho III, foi equivalente a $55,50 \%$ do total queimado, ou seja, $81,80 \%$ da área afetada foram provenientes de incêndios maiores que 100 ha.

Os resultados são distintos dos encontrados em áreas protegidas nacionais (SOARES; SANTOS, 2002; SANTOS; SOARES; BATISTA, 2006), neles, de 1983 a 1987 e de 1994 a 1997 houve uma mesma tendência de diminuição de ocorrências a partir da classe II $(0,1$ - 4,0 ha), contudo, os menores valores foram observados na classe V. Já de 1998 a 2002, a tendência de diminuição começa desde a classe I, 
o que para os autores é altamente desejável, pois para que a eficiência no controle aos incêndios florestais possa ser considerada de bom nível é necessário que a maior concentração das ocorrências seja na classe I. Os resultados apresentados aqui mostram uma discordância neste parâmetro.

De acordo com Wastl et al. (2013), o tamanho médio dos incêndios florestais foi muito diferente nos países alpinos. De 1951 a 2010, o maior tamanho médio de incêndio ocorrido na França durante o verão ( $>8$ ha), provavelmente foi devido às características mediterrânicas da área, enquanto na Alemanha e na Áustria, em ambas as estações, o tamanho médio fogo não excedeu 1,4 ha. No geral, o tamanho médio dos incêndios florestais alpinos foi de 5,6 ha no inverno a 6,4 ha no verão. Grandes incêndios individuais ocorreram principalmente em conexão com longos períodos de seca e em regiões de difícil acesso, sendo as operações de combate muito difíceis. O maior incêndio individual (11.580 ha) foi registrado na parte mediterrânica da França. Este episódio foi extraordinário para a Europa Central, mas em comparação com eventos extremos em outros países como Austrália ou Canadá, em que os incêndios de mais de 100.000 ha não são incomuns, foi relativamente pequeno. Na China, o tamanho da maioria dos incêndios florestais é menor que 100 ha, e apenas 0,21\% são maiores do que 100 ha (TIAN et al., 2013). No sul da França, de acordo com Ganteaume e Jappiot (2013), de 1997 a 2010, ocorreram 260 grandes incêndios $(\geqslant 100 \mathrm{ha})$, representando $0,82 \%$ do número total de incêndios registrados durante o período, enquanto $72 \%$ dos incêndios foram menores do que 1 ha. No entanto, estes grandes incêndios foram responsáveis por 78\% da área queimada (143.140 ha). No Bohemian Switzerland National Park (BSNP), Adámek et al. (2015) encontraram a frequência média de 2 focos por ano e dimensão média de 0,75 ha por ocorrência, sendo $o$ maior incêndio registrado de 17,92 ha.

TABELA 1: Classes de tamanho das ocorrências de incêndios florestais no Parque Estadual da Serra do Brigadeiro (PESB) e entorno de 2007 a 2015.

TABLE 1: Size classes of forest fire occurrences in the Parque Estadual da Serra do Brigadeiro (PESB) and surroundings from 2007 to 2015.

\begin{tabular}{c|c|cc|c}
\hline \multirow{2}{*}{ Classe } & \multicolumn{2}{|c}{ Incêndios } & \multicolumn{2}{c}{ Área queimada } \\
\cline { 2 - 5 } & N. & $\%$ & ha & $\%$ \\
\hline I $(<0,1$ ha $)$ & 0 & 0 & 0 & 0 \\
\hline II $(0,1-4,0$ ha $)$ & 6 & 17,65 & 9,28 & 0,64 \\
\hline III $(4,1-40,0$ ha $)$ & 16 & 47,06 & 188,27 & 13,08 \\
\hline IV $(40,1-200,0$ ha $)$ & 11 & 32,35 & 1004,72 & 69,81 \\
\hline V ( $>200$ ha $)$ & 1 & 2,94 & 237,05 & 16,47 \\
\hline Total & 34 & 100 & 1439,32 & 100 \\
\hline
\end{tabular}

Em que: $\mathrm{N}=$ Número de incêndios.

Analisando o uso e cobertura do solo (Tabela 2), observou-se que a vegetação herbácea foi a mais afetada. A maior área queimada de campo sobre rocha em comparação com campo sobre solo pode estar relacionada com a capacidade de armazenamento de água maior no solo, que dificulta a propagação do fogo. Resultados semelhantes na Colômbia, encontraram Armenteras-Pascual, Retana-Alumbreros e MolownyHoras (2011), comparando o tamanho da área queimada de acordo com a vegetação, mostraram que a vegetação campestre foi o tipo mais queimado, seguido por capoeira, florestas e áreas agrícolas. O padrão para o número de ocorrências foi bastante diferente, no entanto, a vegetação campestre novamente mostrou o valor mais alto, seguido de perto por zonas agrícolas, florestas e capoeira. No Parque Nacional do Itatiaia, Aximoff e Rodrigues (2011) observaram que a maioria dos incêndios ocorreu em área de pastagens (49\%), contudo, a maior extensão atingida foi nos campos de altitude (49,6\%). Também em Ubá (TORRES et al., 2014) e Viçosa (PEZZOPANE; OLIVEIRA NETO; VILELA, 2001), municípios localizados na Zona da Mata mineira, a cerca de 50 quilômetros de distância do PESB, a vegetação herbácea apresentou maior perigo de ocorrências. 
De acordo com Ganteaume e Jappiot (2013), isto pode ser explicado pela vegetação herbácea ser mais influenciada pelas condições atmosféricas reinantes em um dado momento, o que a torna mais seca do que outras tipologias vegetais, em um período de tempo mais curto. Por outro lado, segundo Araújo et al. (2013), a vegetação florestal, devido à alta umidade retida no sistema, sobretudo no solo e entorno (raízes, resíduos vegetais e líter), dificulta a ocorrência do fogo, porém, quando ocorre, é verificado que este ecossistema não possui defesa e é bastante vulnerável aos incêndios.

TABELA 2: Áreas das classes e áreas queimadas de acordo com o uso e cobertura do solo no Parque Estadual da Serra do Brigadeiro (PESB) e entorno de 2007 a 2015.

TABLE 2: Areas of classes and burned areas according to the land use in Parque Estadual da Serra do Brigadeiro (PESB) and surroundings from 2007 to 2015.

\begin{tabular}{c|c|c|c|c|c}
\hline \multirow{2}{*}{ Uso e cobertura do solo } & \multicolumn{2}{|c|}{ Área da classe } & \multicolumn{2}{c|}{ Área queimada } & \multirow{2}{*}{$\begin{array}{c}\text { \% de área queimada } \\
\text { em relação à área da classe }\end{array}$} \\
\cline { 2 - 5 } & ha & $\%$ & ha & $\%$ & 2,1 \\
\hline Mata nativa & 13714,17 & 45,5 & 288,11 & 20,02 & 2,72 \\
\hline Pastagem & 6661,17 & 22,1 & 181,14 & 12,59 & 2,73 \\
\hline Culturas agrícolas & 1489,57 & 4,94 & 40,66 & 2,82 & 2,98 \\
\hline Eucalipto & 229,65 & 0,76 & 6,84 & 0,48 & 10,17 \\
\hline Campo sobre rocha & 4847,98 & 16,08 & 493,2 & 34,27 & 13,42 \\
\hline Campo sobre solo & 3198,51 & 10,61 & 429,37 & 29,83 & 4,78 \\
\hline Total & $30.141,05$ & 100 & 1439,32 & 100 &
\end{tabular}

Na República Tcheca, Adámek et al. (2015) concluíram que os incêndios são mais frequentes nas seguintes áreas (em ordem decrescente de importância): (1) vertentes convexas com solos arenosos mais rasos (maior taxa de evaporação) e vegetação com reduzida densidade de copa; (2) vertentes com maior exposição solar; (3) áreas com maior abundância de coníferas; (4) áreas de florestas mais antigas (maior acúmulo de combustíveis e menor densidade de dossel); e (5) áreas próximas às aldeias, estradas, caminhos turísticos e outros locais da atividade humana.

No PESB, a influência do relevo (por meio de suas interações com os elementos climatológicos) favorecem as ocorrências em áreas de maior declividade. Apesar da área queimada das classes $30^{\circ}$ a $40^{\circ}$ e $>40^{\circ}$ (Tabela 3) não apresentarem os maiores valores absolutos, a porcentagem de área queimada em relação ao tamanho das áreas com estas declividades são maiores nestas classes, em que um quantitativo referente a $16,27 \%$ das áreas acima de $30^{\circ}$ foram queimadas dentro do recorte temporal estudado, este percentual diminui paralelamente à diminuição da declividade.

Adámek et al. (2015), sobre este fato, argumentam que em regiões em que o clima é mais úmido, a tendência é que a irregularidade do relevo favoreça as ocorrências dos incêndios. Corroborando, para Ganteaume e Jappiot (2013), vários estudos que mostram que a probabilidade de ocorrência de grandes incêndios é maior em áreas de alta rugosidade topográfica que podem facilitar a ocorrência e propagação do fogo e limitam o acesso para o combate. 
TABELA 3: Áreas das classes e áreas queimadas de acordo com a declividade no Parque Estadual da Serra do Brigadeiro (PESB) e entorno de 2007 a 2015.

TABLE 3: Areas of classes and burned areas according to the slope in Parque Estadual da Serra do Brigadeiro (PESB) and surroundings from 2007 to 2015.

\begin{tabular}{c|c|c|c|c|c}
\hline \multirow{2}{*}{ Declividade } & Área da classe & \multicolumn{2}{|c|}{ Área queimada } & \multirow{2}{*}{$\%$ de área queimada em relação à área da classe } \\
\cline { 2 - 5 } & ha & $\%$ & ha & $\%$ & 2,65 \\
\hline 0 a $10^{\circ}$ & 5723,19 & 18,99 & 151,38 & 10,52 & 3,8 \\
\hline 10,1 a $20^{\circ}$ & 10170,45 & 33,74 & 386,46 & 26,85 & 5,21 \\
\hline 20,1 a $30^{\circ}$ & 7903,25 & 26,22 & 411,4 & 28,58 & 6,85 \\
\hline 30,1 a $40^{\circ}$ & 4187,62 & 13,89 & 286,99 & 19,94 & 9,42 \\
\hline$>40,1^{\circ}$ & 2156,54 & 7,15 & 203,09 & 14,11 & 4,78 \\
\hline TOTAL & $30.141,05$ & 100 & 1439,32 & 100 & \\
\hline
\end{tabular}

Também a altitude influencia nas ocorrências de incêndios visto que determina a quantidade de material combustível, bem como, sua umidade, as mesmas tendem a diminuir com maiores altitudes. A altitude pode diminuir a probabilidade de ocorrência de incêndios, uma vez que em área mais elevadas apresentam uma quantidade maior de precipitação, assim como temperaturas mais baixas, o que eleva o teor de umidade dos combustíveis mortos (NIETO et al., 2012). Na China, a maioria dos incêndios florestais ocorre em áreas de baixa altitude. No total, $54 \%$ queimaram áreas com altitudes inferiores a $500 \mathrm{~m}, 20 \%$ de 501 a $1000 \mathrm{~m}$ e $15 \%$ de 1001 a $2000 \mathrm{~m}$. Apenas $10 \%$ dos incêndios ocorreram em áreas com uma altitude acima de $2000 \mathrm{~m}$ (TIAN et al., 2013).

Por outro lado, com o aumento da altitude, há uma diminuição do porte da vegetação, a partir de certa cota altimétrica, as fisionomias florestais dão lugar às formas campestres, mais propícias às ocorrências. Esta dicotomia é bem representada no PESB (Tabela 4). Existe um aumento da área queimada com aumento da altitude, em função da modificação do material combustível e posterior declínio da área queimada, em função do aumento da umidade do ar.

TABELA 4: Áreas das classes e áreas queimadas de acordo com a altitude no Parque Estadual da Serra do Brigadeiro (PESB) e entorno de 2007 a 2015.

TABLE 4: Areas of classes and burned areas according to the elevation and the Parque Estadual da Serra do Brigadeiro (PESB) surroundings from 2007 to 2015.

\begin{tabular}{c|c|c|c}
\hline \multirow{2}{*}{ Altitude (m) } & Área da classe & \multicolumn{2}{|c}{ Área queimada } \\
\cline { 2 - 4 } & $($ ha $)$ & ha & $\%$ \\
\hline $768-1074$ & 6023,6 & 89,22 & 6,2 \\
\hline $1074-1214$ & 6023,6 & 327,81 & 22,78 \\
\hline $1214-1345$ & 6023,6 & 424,35 & 29,48 \\
\hline $1345-1478$ & 6023,6 & 368,42 & 25,6 \\
\hline $1478-1985$ & 6023,6 & 229,52 & 15,95 \\
\hline TOTAL & $30.118,00$ & 1439,32 & 100 \\
\hline
\end{tabular}

Para Gralewicz, Nelson e Wulder (2012), embora a relação entre a elevação e grandes incêndios varia em escala regional, no Canadá foi observado o limiar de $1000 \mathrm{~m}$, semelhante aos limites encontrados em outros estudos (1500 m em Washington; $800 \mathrm{~m}$ no Alasca; $1000 \mathrm{~m}$ no Mediterrâneo), no PESB este limite está a $1798 \mathrm{~m}$.

Além do aspecto topográfico, a exposição das vertentes ao sol (Tabela 5) também mostra o controle climático sobre as ocorrências. Esta distribuição se deve ao fato de superfícies com orientações e inclinações diferentes receberem quantidades diferentes de radiação solar global, em comparação com uma superfície 
plana, em uma mesma localidade e época do ano (TORRES; MACHADO, 2011).

Durante grande parte do ano, o sol culmina no zênite ao norte do PESB. Este fator tende a elevar a temperatura nas vertentes de orientação norte, influenciando diretamente nas características físicas do material combustível e ocorrências de incêndios.

A diferença entre as vertentes voltadas para o oeste e para o leste pode ser explicada pela vertente oeste receber maior quantidade de energia na parte da tarde, quando a superfície terrestre e o ar já estão aquecidos e normalmente não existe neblina. Além destes, as vertentes voltadas para o leste recebem ventos úmidos vindos do Oceano Atlântico, distante, em linha reta, cerca de $200 \mathrm{~km}$ do parque.

Corroborando, Hugget (1995) destaca que no Hemisfério Sul, encostas orientadas para o norte recebem maior insolação do que as voltadas para o sul, que, por sua vez, recebem maiores precipitações devido aos ventos carregados de umidade vindos do mar (SW, S e SE). Oliveira et al. (1995), em estudos conduzidos no Maciço da Tijuca (RJ), encontraram diferenças significativas para as duas vertentes no que diz respeito a parâmetros como temperatura, precipitação e umidade. Segundo esses autores, as encostas voltadas para o sul possuem serapilheira em média $41,9 \%$ mais úmida que as voltadas para o norte. Os autores afirmam ainda que a perda desta umidade também se dá muito mais rápido nas encostas voltadas para o norte, pois as voltadas para o sul retêm 1,6 vezes mais umidade. Consequentemente, a umidade do solo se comporta da mesma maneira, apenas variando de acordo com o tipo de cobertura vegetal a que está associado.

Esta variação de umidade se reflete basicamente em função dos diferentes índices de temperatura destes dois tipos de encosta, visto que as encostas voltadas para o norte são significativamente mais quentes, devido à maior incidência de raios solares que as voltadas para o sul, observando $98 \%$ das ocorrências de temperaturas máximas. As temperaturas mínimas também ocorreram em grande maioria $(86 \%)$ nas encostas norte, o que deve ser atribuído à maior umidade relativa na face sul, tendo em vista o maior período de deposição de orvalho que atua como um efeito "tampão" reduzindo as temperaturas extremas (OLIVEIRA et al., 1995).

TABELA 5: Áreas das classes e áreas queimadas de acordo com a exposição das vertentes ao sol no Parque Estadual da Serra do Brigadeiro (PESB) e entorno de 2007 a 2015.

TABLE 5: Areas of classes and burned areas according to the aspect in the Parque Estadual da Serra do Brigadeiro (PESB) and surroundings from 2007 to 2015.

\begin{tabular}{c|c|c|c|c|c}
\hline \multirow{2}{*}{$\begin{array}{c}\text { Exposição das } \\
\text { vertentes }\end{array}$} & \multicolumn{2}{|c|}{ Área da classe } & \multicolumn{2}{|c|}{ Área queimada } & \multirow{2}{*}{$\begin{array}{c}\text { \% de área queimada em relação à área da } \\
\text { classe }\end{array}$} \\
\cline { 2 - 5 } & ha & $\%$ & ha & $\%$ & 3,46 \\
\hline Sul & 7349,13 & 24,38 & 253,92 & 17,64 & 3,6 \\
\hline Leste & 8321,45 & 27,61 & 299,51 & 20,81 & 5,49 \\
\hline Oeste & 7238,85 & 24,02 & 397,34 & 27,61 & 6,76 \\
\hline Norte & 7231,62 & 23,99 & 488,55 & 33,94 & 4,78 \\
\hline TOTAL & $30.141,05$ & 100 & $1.439,32$ & 100 & \\
\hline
\end{tabular}

Com relação às distâncias das vias de acesso, observou-se no PESB e entorno que quanto mais próximo, maior a área queimada. Na região não foi observado nenhum incêndio a mais de $2 \mathrm{~km}$ de uma via e $84,13 \%$ das áreas queimadas estão a menos de $1 \mathrm{~km}$ (Tabela 6).

No estado do Amazonas, a maior parte da floresta afetada pelos incêndios também é adjacente às estradas (VASCONCELOS et al., 2013). Para Gralewicz, Nelson e Wulder (2012), no Canadá, a acessibilidade humana foi o principal fator de aumento da suscetibilidade a incêndios florestais. Fatores bióticos e topográficos foram considerados secundários.

Segundo Keeley, Fotheringham e Moritz (2004) e Stephens (2005), esta condição pode ser explicada visto que as ocorrências de incêndios florestais causadas por atividades antrópicas são observadas com frequência ao longo dos corredores de transporte (trilhas, rodovias e ferrovias). Este fator é tão importante que Ganteaume e Jappiot (2013) sugerem que as medidas destinadas a reduzir a ameaça de incêndios devem primeiro levar em consideração as margens de estradas secundárias, que fazem fronteira com áreas de 
campos e de pastagem, proporcionando assim uma quebra de combustível em áreas onde os incêndios são mais propensos a iniciar e se propagar. Na Tailândia, grande parte dos incêndios ocorriam em uma faixa de cerca de $20 \mathrm{~m}$ ao longo de cada lado das estradas principais, e muitas vezes se propagavam para terrenos florestais e agrícolas. Este problema foi reduzido em 2000 pelo plantio de árvores ao longo das principais vias (HOARE, 2004).

Por outro lado, na Suécia, Drobyshev, Niklasson e Linderholm (2012) observaram que o desenvolvimento de uma rede de estradas florestais densas ajudou a reduzir o intervalo de tempo entre a detecção e o ataque inicial pelos bombeiros, o que pode ter sido uma das condições mais importantes para a supressão eficaz do fogo, segundo os autores.

TABELA 6: Áreas das classes e áreas queimadas de acordo com a proximidade de trilhas e estradas no Parque Estadual da Serra do Brigadeiro (PESB) e entorno de 2007 a 2015.

TABLE 6: Areas of classes and burned areas according to the proximity of trails and roads in Parque Estadual da Serra do Brigadeiro (PESB) and surroundings from 2007 to 2015.

\begin{tabular}{c|c|c|c|c}
\hline \multirow{2}{*}{ Proximidade comtrilhas e estradas $(\mathrm{m})$} & \multicolumn{2}{|c|}{ Área da classe } & \multicolumn{2}{c}{ Área queimada } \\
\cline { 2 - 5 } & ha & $\%$ & ha & $\%$ \\
\hline 0 a 500 & 14169,51 & 47,01 & 609,96 & 42,38 \\
\hline 500 a 1000 & 8579,63 & 28,46 & 600,97 & 41,75 \\
\hline 1000 a 1500 & 4814,47 & 15,97 & 120,04 & 8,34 \\
\hline 1500 a 2000 & 2142,62 & 7,11 & 108,35 & 7,53 \\
\hline 2000 a 2500 & 434,82 & 1,44 & 0 & 0 \\
\hline Total & $30.141,05$ & 100 & 1439,32 & 100 \\
\hline
\end{tabular}

Com relação aos meses do ano, segundo Wastl et al. (2013), a estação normal de ocorrência de incêndios acontece quando prevalecem os sistemas de alta pressão, que são normalmente associados a condições secas e de muita insolação. No PESB, ocorre no final do inverno e início da primavera (Tabela 7), tendo seu pico em área queimada no mês de setembro. Isto pode ser explicado pelo início da primavera ser a época do ano que o chão da floresta recebe maior radiação solar, porque os dias são mais longos e o crescimento das folhagens ainda não começou. Ao mesmo tempo, o vento preferencial, nesta época, tem um efeito na secagem e aumento da evapotranspiração. Assim, durante este período, a presença de grande quantidade de combustível morto no chão da floresta pode aumentar o potencial de fogo de forma dramática (HUESCA et al., 2009).Uma situação observada e frequente em muitos outros estudos como os de Aximoff e Rodrigues (2011), no Parque Nacional do Itatiaia (RJ), e o de Koproski, Batista e Soares (2004), no Parque Nacional da Ilha Grande (PR), tem sido o fato de que o número mensal de incêndios não está diretamente relacionado com a extensão da área queimada mensal. Além do favorecimento das ocorrências por conta das condições atmosféricas, Mendes (2014), em estudo junto aos moradores do entorno do PESB, observou que o fogo é utilizado como forma de manejo agrícola, principalmente no período de julho a outubro.

$\mathrm{Na}$ China, a maioria dos incêndios ocorre na primavera, sendo março o mês com maior número de incêndios $(60,0 \%)$, seguido de abril $(13,1 \%)$, fevereiro $(10,9 \%)$, dezembro $(7,3 \%)$, e outros meses $(0,2-$ $3,8 \%$ ) (TIAN et al., 2013). Esta mesma tendência foi observada na Índia, onde os incêndios florestais ocorrem principalmente de fevereiro a abril (SCHMERBECK; KOHLI; SEELAND, 2015); em Nova York com mais de $60 \%$ dos incêndios florestais ocorrendo na primavera (abril e maio) (IRLAND, 2013); e na Alemanha, Holsten et al. (2013) mostraram um aumento acentuado no período de março a abril.

Na Suécia, também foi observado o pico de ocorrências durante a primavera, de abril a agosto, o nível permaneceu relativamente constante, em alguns casos com um ligeiro aumento no final do verão. De agosto a setembro, uma forte queda no número médio de ocorrências foi observada, o que denota o fim da época de incêndios no país (DROBYSHEV; NIKLASSON; LINDERHOLM, 2012).

Nos Alpes, segundo Wastl et al. (2013), a área total queimada no verão (57\%) foi maior do que no inverno (43\%), mas as diferenças regionais foram grandes. Enquanto na Alemanha $50 \%$ da área queimada 
ocorreram durante os meses de verão, essa fração foi consideravelmente maior nos países do sul dos Alpes como França (88\%) e Eslovénia (71\%). Na Suíça e na Áustria, a área queimada foi maior durante o inverno. Este fato é conhecido da literatura e foi atribuído ao caráter propagação rápida dos incêndios que ocorrem no inverno nas florestas de folhosas decíduas. Diferenças sazonais, no número de incêndios florestais, também apresentaram maiores percentuais de incêndios de verão na França (69\%), devido à porção importante da área Mediterrânica (caracterizada como verões secos e invernos chuvosos), enquanto na Itália $41 \%$ dos incêndios ocorreram nesta estação. Também Ganteaume e Jappiot (2013), no sul da França, encontraram maior número de ocorrências no verão. Já uma região de clima temperado na Península Ibérica apresentou dois picos de ocorrências de incêndios florestais, um na primavera (fevereiro ou março) e outro no verão (agosto), enquanto a parte mediterrânica apresentou seu pico no verão (HUESCA et al., 2009).

Segundo Aximoff e Rodrigues (2011), pode-se perceber a sobreposição entre os meses mais críticos para o fogo e a estação de seca, o que pode estar relacionado ao período quando o fogo é utilizado como ferramenta para a renovação da pastagem, por exemplo. Portanto, as medidas de prevenção aos incêndios devem ser implementadas nos meses anteriores ao período crítico e reforçadas durante este.

A ocorrência e a propagação dos incêndios florestais estão fortemente associadas às condições climáticas. A intensidade de um incêndio e a velocidade com que ele se propaga estão diretamente ligadas à umidade relativa, à temperatura e à velocidade do vento (SORIANO; DANIEL; SANTOS, 2015). Analisando-se a influência dos elementos meteorológicos sobre as ocorrências e incêndios (Tabela 7), observou-se que a umidade relativa do ar (UR\%) apresentou a maior correlação tanto em número de ocorrências como em área queimada.

$\mathrm{Na}$ Alemanha, a variável meteorológica mais correlacionada com as ocorrências de incêndios, em 9 dos 13 estados estudados, também foi a umidade relativa, sendo que a menor correlação encontrada também foi para a temperatura (HOLSTEN et al., 2013). Para os autores, é plausível que a umidade relativa seja um bom indicador das condições de ocorrência de incêndio, já que inclui indiretamente informações sobre temperatura, precipitação e processos biofísicos dos arredores. A temperatura por sua vez é mascarada pela sazonalidade, a estação mais quente do ano (verão) na maior parte da região tropical também é a estação mais úmida, o que dificulta as ocorrências. Alguns elementos do clima mostraram influências distintas sobre a ignição e a propagação do fogo, a maior correlação entre área queimada e a velocidade do vento, em comparação com correlação entre o número de ocorrências e este elemento, mostrou que o vento ajuda mais o fogo a se propagar do que se iniciar, o contrário acontecendo com a insolação, precipitação e temperatura $\left(\mathrm{T}^{\circ} \mathrm{C}\right)$, estes elementos têm maior influência sobre a ignição.

TABELA 7: Coeficiente de correlação de Pearson (r) entre elementos meteorológicos médios mensais e as ocorrências de incêndios e comparação do número de ocorrências de incêndios e áreas queimadas de acordo com os meses do ano no PESB e entorno de 2007 a 2015 pelo teste Scott Knott a 5\% de probabilidade.

TABLE 7: $\quad$ Pearson correlation coefficient (r) between monthly average weather elements and fire occurrences and comparing the number of burning fires and areas of occurrences according to the months of the year in PESB and surroundings from 2007 to 2015 by Scott test Knott at 5\% probability.

\begin{tabular}{c|c|c|c|c|c|c|c|c}
\hline Meses & $\begin{array}{c}\text { Vento } \\
(\mathrm{m} / \mathrm{s})\end{array}$ & $\begin{array}{c}\text { Evaporação } \\
(\mathrm{mm})\end{array}$ & $\begin{array}{c}\text { Insolação } \\
\text { (horas) }\end{array}$ & Precipitação $(\mathrm{mm})$ & $\mathrm{T}\left({ }^{\circ} \mathrm{C}\right)$ & $\begin{array}{c}\text { UR } \\
(\%)\end{array}$ & $\mathrm{N}$. & $\begin{array}{c}\text { Área queimada } \\
(\text { ha })\end{array}$ \\
\hline Jan & 1,21 & 72,26 & 160,29 & 232,05 & 22,69 & 79,28 & $2 \mathrm{a}$ & $13 \mathrm{a}$ \\
\hline Fev & 1,41 & 79,04 & 191,41 & 90,18 & 22,99 & 76,67 & $2 \mathrm{a}$ & $32,33 \mathrm{a}$ \\
\hline Mar & 0,81 & 66,83 & 171,55 & 190,26 & 22,33 & 82,03 & $0 \mathrm{a}$ & $0 \mathrm{a}$ \\
\hline Abr & 0,85 & 57,76 & 172,84 & 65,84 & 20,74 & 82,7 & $0 \mathrm{a}$ & $0 \mathrm{a}$ \\
\hline Mai & 0,88 & 58,15 & 189,86 & 32,6 & 17,88 & 82,44 & $0 \mathrm{a}$ & $0 \mathrm{a}$ \\
\hline Jun & 0,88 & 53,35 & 180,04 & 16,04 & 16,71 & 83 & $0 \mathrm{a}$ & $0 \mathrm{a}$ \\
\hline Jul & 0,92 & 67,46 & 206,18 & 6,84 & 16,56 & 80,04 & $0 \mathrm{a}$ & $0 \mathrm{a}$ \\
\hline Ago & 1,02 & 90,74 & 203,01 & 5,74 & 17,63 & 73,06 & $14 \mathrm{~b}$ & $168,05 \mathrm{a}$ \\
\hline
\end{tabular}


TABELA 7: Continuação...

TABLE 7: Continued..

\begin{tabular}{c|c|c|c|c|c|c|c|c}
\hline Meses & $\begin{array}{c}\text { Vento } \\
(\mathrm{m} / \mathrm{s})\end{array}$ & $\begin{array}{c}\text { Evaporação } \\
(\mathrm{mm})\end{array}$ & $\begin{array}{c}\text { Insolação } \\
\text { (horas) }\end{array}$ & Precipitação $(\mathrm{mm})$ & $\mathrm{T}\left({ }^{\circ} \mathrm{C}\right)$ & $\begin{array}{c}\text { UR } \\
(\%)\end{array}$ & $\mathrm{N}$. & $\begin{array}{c}\text { Área queimada } \\
(\text { ha })\end{array}$ \\
\hline Set & 1,48 & 107,33 & 183,83 & 47,41 & 19,51 & 68,13 & $11 \mathrm{~b}$ & $1028,46 \mathrm{~b}$ \\
\hline Out & 1,4 & 99,91 & 150,1 & 92,36 & 21,1 & 72,68 & $3 \mathrm{a}$ & $186,7 \mathrm{a}$ \\
\hline Nov & 1,37 & 74,06 & 131,7 & 209,04 & 21,47 & 78,47 & $2 \mathrm{a}$ & $10,78 \mathrm{a}$ \\
\hline Dez & 1,23 & 71,98 & 143,13 & 322,95 & 22,62 & 80,38 & $0 \mathrm{a}$ & $0 \mathrm{a}$ \\
\hline r n. & 0,35 & 0,75 & 0,31 & $-0,33$ & $-0,22$ & $-0,82$ & - & - \\
\hline r área & 0,51 & 0,75 & 0,14 & $-0,24$ & $-0,1$ & $-0,81$ & - & - \\
\hline
\end{tabular}

Em que: N. = Número de incêndios. Médias dos valores seguidos de mesma letra não diferem estatisticamente entre si pelo teste Scott Knott a 5\% de probabilidade.

A análise conduzida por Collins (2014) demonstrou uma forte tendência para o aumento das ocorrências de incêndios de acordo com variações anormais do tempo atmosférico ao longo das últimas décadas, apresentando alguns anos mais quentes e secos, ou padrões climáticos sinóticos de baixa frequência. No PESB, a influência climática também foi observada na distribuição de incêndios e de área queimada de acordo com o ano (Tabela 8). Com relação ao número de ocorrências, o ano de 2014 foi o que apresentou o maior valor, também apresentando a maior área queimada e segunda maior média de área queimada por ocorrência. Este fato pode estar relacionado ao ano apresentar o menor valor de precipitação acumulada da série $(824,6 \mathrm{~mm})$, bem inferior à média de 1403,26 mm que o período apresentou. O segundo pior ano, em termos de precipitação, foi $2007(1009,5 \mathrm{~mm})$, apresentando também a segunda maior área queimada.

TABELA 8: Áreas das classes e áreas queimadas de acordo com o ano no Parque Estadual da Serra do Brigadeiro (PESB) e entorno de 2007 a 2015.

TABLE 8: Areas of classes and burned areas according to the year in Parque Estadual da Serra do Brigadeiro (PESB) and surroundings from 2007 to 2015.

\begin{tabular}{c|c|c|c|c|c}
\hline \multirow{2}{*}{ Anos } & \multicolumn{2}{|c|}{ Ocorrências } & \multicolumn{2}{c|}{ Área queimada } & \multirow{2}{*}{ Área queimada por ocorrência (ha/inc.) } \\
\cline { 2 - 5 } & N. & $\%$ & ha & $\%$ & 47,84 \\
\hline 2007 & 7 & 20,59 & 334,9 & 23,27 & 5,89 \\
\hline 2008 & 1 & 2,94 & 5,89 & 0,41 & 0 \\
\hline 2009 & 0 & 0 & 0 & 0 & 0 \\
\hline 2010 & 0 & 0 & 0 & 0 & 76,19 \\
\hline 2011 & 3 & 8,82 & 228,57 & 15,88 & 27,53 \\
\hline 2012 & 5 & 14,71 & 137,67 & 9,56 & 9,35 \\
\hline 2013 & 7 & 20,59 & 65,42 & 4,55 & 66,04 \\
\hline 2014 & 9 & 26,47 & 594,36 & 41,29 & 36,26 \\
\hline 2015 & 2 & 5,88 & 72,51 & 5,04 & 42,33 \\
\hline TOTAL & 34 & 100 & $1.439,32$ & 100 &
\end{tabular}

Em que: $\mathrm{N}=$ Número de incêndios.

Apesar de terem ocorrido apenas três incêndios em 2011, foi o ano que apresentou a segunda maior área queimada e maior média de área queimada por ocorrência, embora sua precipitação tenha sido pouco acima da média do período analisado $(1433,8 \mathrm{~mm})$. Todas as 3 ocorrências foram observadas no mês de setembro, que para este ano apresentou o menor valor de precipitação acumulada $(4,8 \mathrm{~mm})$, bem inferior 
à média do mês dentro do período estudado $(56,5 \mathrm{~mm})$. Os anos que apresentaram ocorrências no mês de janeiro (2013 e 2015) foram precedidos pelos 2 meses de dezembro mais secos da série, o de 2012 (199,3 $\mathrm{mm})$ e o de $2014(167,6 \mathrm{~mm})$, valores inferiores aos $350,9 \mathrm{~mm}$ de precipitação acumulada média para o mês dentro do período.

\section{CONCLUSÕES}

De acordo com os resultados, concluiu-se que:

- As principais causas dos incêndios estão relacionadas às condições antrópicas, contudo, as condições ambientais podem propiciar um cenário favorável para o desenvolvimento do evento;

- Com relação às classes de tamanho das áreas queimadas, os resultados aqui apresentados justificam maior atenção, pois estão aquém daqueles observados em outros estudos;

- Vertentes com exposição norte, mais inclinadas e com altitudes medianas (em relação às observadas na área de estudo) se apresentaram como as mais afetadas;

- A vegetação herbácea foi a mais atingida na região durante o período de análise;

- A umidade relativa do ar foi o elemento meteorológico mais correlacionado com as ocorrências mensais, levando os meses de agosto e setembro a compor a estação normal de perigo de incêndios na região, sendo que o pico do número de ocorrências foi observado em agosto e a maior área queimada em setembro.

\section{REFERÊNCIAS}

ADÁMEK, M. et al. Forest fires within a temperate landscape: a decadal and millennial perspective from a sandstone region in Central Europe. Forest Ecology and Management, Amsterdam, v. 336, p. 81-90, 2015.

ARAÚJO, H. J. B. et al. Danos provocados pelo fogo sobre a vegetação natural em uma floresta primária no estado do Acre, Amazônia brasileira. Ciência Florestal, Santa Maria, v. 23, n. 2, p. 297-308, 2013.

ARMENTERAS-PASCUAL, D.; RETANA-ALUMBREROS, J.; MOLOWNY-HORAS, R. Characterising fire spatial pattern interactions with climate and vegetation in Colombia. Agricultural and Forest Meteorology, Amsterdam, v. 151, p. 279-289, 2011.

AXIMOFF, I.; RODRIGUES, R. C. Histórico dos incêndios florestais no Parque Nacional do Itatiaia. Ciência Florestal, Santa Maria, v. 21, n. 1, p. 83-92, 2011.

COLLINS, R. D. Fire weather and large fire potential in the northern Sierra Nevada. Agricultural and Forest Meteorology, Amsterdam, v. 189/190, p. z30-35, 2014.

COLLINS, R. D. et al. Forest fire management to avoid unintended consequences: a case study of Portugal using system dynamics. Journal of Environmental Management, London, v. 130, p. 1-9, 2013.

DROBYSHEV, I.; NIKLASSON, M.; LINDERHOLM, H. W. Forest fire activity in Sweden: climatic controls and geographical patterns in 20th century. Agricultural and Forest Meteorology, Amsterdam, v. 154/155, p. 174-186, 2012.

FIEDLER, N. C.; MERLO, D. A.; MEDEIROS, M. B. Ocorrência de incêndios florestais no Parque Nacional da Chapada dos Veadeiros, Goiás. Ciência Florestal, Santa Maria, v. 16, n. 2, p. 153-161, 2006. FUENTES-SANTOS, I.; MAREY-PÉREZ, M. F.; GONZÁLEZ-MANTEIGA, W. Forest fire spatial pattern analysis in Galicia (NW Spain). Journal of Environmental Management, London, v. 128, p. 30-42, 2013. GANTEAUME, A.; JAPPIOT, M. What causes large fires in Southern France. Forest Ecology and Management, Amsterdam, v. 294, p. 76-85, 2013.

GRALEWICZ, N. J.; NELSON, T. A.; WULDER, M. A. Factors influencing national scale wildfire susceptibility in Canada. Forest Ecology and Management, Amsterdam, v. 265, p. 20-29, 2012.

HOARE, P. A process for community and government cooperation to reduce the forest fire and smoke problem in Thailand. Agriculture, Ecosystems and Environment, Amsterdam, v. 104, p. 35-46, 2004. HOLSTEN, A. et al. Evaluation of the performance of meteorological forest fire indices for German federal states. Forest Ecology and Management, Amsterdam, v. 287, p. 123-131, 2013. 
HUESCA, M. et al. Assessment of forest fire seasonality using MODIS fire potential: a time series approach. Agricultural and Forest Meteorology, Amsterdam, v. 149, n. 11, p. 1946-1955, 2009.

HUGGET, R. J. Geoecology: an evaluation approach. Londres: London, 1995.

IRLAND, L. C. Extreme value analysis of forest fires from New York to Nova Scotia, 1950-2010. Forest Ecology and Management, Amsterdam, v. 294, p. 150-157, 2013.

KEELEY, J. E.; FOTHERINGHAM, C. J.; MORITZ, M. A. Lessons from the 2003 wildfires in southern California. Journal of Forestry, Bethesda, v. 102, p. 26-31, 2004.

KOPROSKI, L. P.; BATISTA, A. C.; SOARES, R. V. Ocorrências de incêndios florestais no Parque Nacional de Ilha Grande - Brasil. Floresta, Curitiba, v. 34, n. 2, p. 193-197, 2004.

LINN, R. R. et al. Using periodic line fires to gain a new perspective on multi-dimensional aspects of forward fire spread. Agricultural and Forest Meteorology, Amsterdam, v. 157, p. 60-76, 2012.

MAVSAR, R.; CABÁN, A. G.; FARRERAS, V. The importance of economics in fire management programmes analysis. Towards Integrated Fire Management - Outcomes of the European Project Fire Paradox. [s. 1.: s. n.], 2010. 230 p.

MEDEIROS, M. B.; FIEDLER, N. C. Incêndios florestais no Parque Nacional da Serra da Canastra: desafios para a conservação da biodiversidade. Ciência Florestal, Santa Maria, v. 14, n. 2, p. 157-168, 2004.

MENDES, A. E. O. Incêndios florestais, diálogos e interações entre agricultores do entorno de unidade de conservação. 2014. 106 f. Dissertação (Mestrado em Agroecologia) - Universidade Federal de Viçosa, Viçosa, MG, 2014.

NIETO, H. et al. Lightning-caused fires in Central Spain: development of a probability model of occurrence for two Spanish regions. Agricultural and Forest Meteorology, Amsterdam, v. 162/163, p. 35-43, 2012.

OKANO, Y.; YAMANO, H. Forest fire propagation simulations for a risk assessment methodology development for a nuclear power plant. Case Studies in Fire Safety, [s. 1.], v. 4, p. 1-10, 2015.

OLIVEIRA, R. R. et al. Significado ecológico da orientação de encostas no Maciço da Tijuca. Oecologia Brasiliensis, Rio de Janeiro, v. 1, p. 523-541, 1995.

PAULA, T. A. R. et al. Aspectos do uso territorial por onça parda (Puma concolor), através de monitoramento via satélite, na região do Parque Estadual da Serra do Brigadeiro, MG. Arquivo Brasileiro de Medicina Veterinária e Zootecnia, Belo Horizonte, v. 67, n. 1, p. 80-88, 2015.

PEREIRA, C. A.; FIEDLER, N. C.; MEDEIROS, M. B. Análise de ações de prevenção e combate aos incêndios florestais em unidades de conservação do cerrado. Floresta, Curitiba, v. 34, n. 2, p. 95-100, 2004. PEREIRA, A. A. et al. dos. Análise da distribuição espacial de áreas queimadas através da função $\mathrm{K}$ de Ripley. Scientia Forestalis, Piracicaba, v. 41, n. 100, p. 445-455, 2013.

PEZZATTI, G. B. et al. Fire regime shifts as a consequence of fire policy and socio-economic development: an analysis based on the change point approach. Forest Policy and Economics, Amsterdam, v. 29, p. 7-18, 2013.

PEZZOPANE, J. E. M.; OLIVEIRA NETO, S. N.; VILELA, M. F. Risco de Incêndio em Função da característica do Clima, Relevo e Cobertura do Solo. Floresta e Ambiente, Seropédica, v. 8 n. 1, p. 167-166, 2001.

RAMSEY, G. S.; HIGGINS, D. G. Canadian forest fire statistics. Ontario: Canadian Forest Service, 1981. SAN-MIGUEL-AYANZ, J.; MORENO, J. M.; CAMIA, A. Analysis of large fires in European Mediterranean landscapes: lessons learned and perspectives. Forest Ecology and Management, Amsterdam, v. 294, p. 11-22, 2013.

SANTOS, J. F.; SOARES, R. V.; BATISTA, A. C. Perfil dos incêndios florestais no Brasil em áreas protegidas no período de 1998 a 2002. Floresta, Curitiba, v. 36, n. 1, p. 93-100, 2006.

SCHMERBECK, J.; KOHLI, A.; SEELAND, K. Ecosystem services and forest fires in India - context and policy implications from a case study in Andhra Pradesh. Forest Policy and Economics, Amsterdam, v. 50, p. 337-346, 2015.

SOARES, R. V.; SANTOS, J. F. Perfil dos incêndios florestais no Brasil de 1994 a 1997. Floresta, Curitiba, v. 32, n. 2, p. 219-232, 2002.

SORIANO, B. M. A.; DANIEL, O.; SANTOS, S. A. Eficiência de índices de risco de incêndios para o Pantanal Sul-mato-grossense. Ciência Florestal, Santa Maria, v. 25, n. 4, p. 809-816, 2015.

STEPHENS, S. L. Forest fire causes and extent on United States Forest Service lands. 
International Journal of Wildland Fire, Clayton South, v. 14, p. 213-222, 2005.

TIAN, X. et al. Distribution characteristics and the influence factors of forest fires in China. Forest Ecology and Management, Amsterdam, v. 310, p. 460-467, 2013.

TORRES, F. T. P. et al. Mapeamento da suscetibilidade a ocorrências de incêndios em vegetação na área urbana de Ubá-MG. Revista Árvore, Viçosa, MG, v. 38, n. 5, p. 811-817, 2014.

TORRES, F. T. P.; MACHADO, P. J. O. Introdução à climatologia. São Paulo: Cengage Learning, 2011. VASCONCELOS, S. S. et al. Forest fires in southwestern Brazilian Amazonia: estimates of area and potential carbon emissions. Forest Ecology and Management, Amsterdam, v. 291, p. 199-208, 2013.

WASTL, C. et al. Large-scale weather types, forest fire danger, and wildfire occurrence in the Alps. Agricultural and Forest Meteorology, Amsterdam, v. 168, n. 2013, p. 15-25, 2013. 